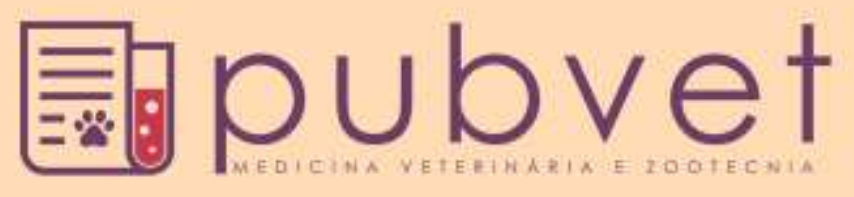

HTTP://DX.DOI.ORG/10.22256/PUBVET.V11N2.187-190

\title{
Criptococose cutânea em um canino: Relato de caso
}

\author{
Inamara Barreto Santos ${ }^{1 *}$, Samy Carvalho Sousa Santos ${ }^{2}$, Kely dos Santos Coutinho', \\ Luana Ferreira Cardoso', Anne Izabella Sobreira Argolo Delfino ${ }^{3}$, Leonardo Alves de \\ Farias $^{3}$

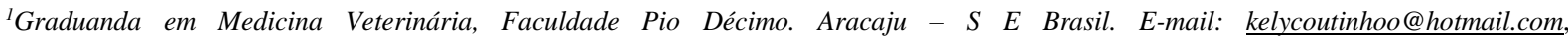 \\ luanacardoso.lfc@hotmail.com, \\ ${ }^{2}$ Médico Veterinário - Prefeitura Municipal de Nossa Senhora do Socorro - SE, Brasil. E-mail: samycrv@hotmail.com \\ ${ }^{3}$ Professor (a) da Faculdade Pio Décimo, Departamento de Medicina Veterinária. Aracaju -SE Brasil. E-mail: anneargolo@bol.com.br, \\ vetleco@yahoo.com.br \\ *Autor para correspondência, E-mail: inamara.barreto@hotmail.com
}

RESUMO. A criptococose é uma doença fúngica multissistêmica de caráter oportunista, de ocorrência mundial, acomete os mais diversos animais, inclusive os seres humanos, sendo que os felinos é a espécie animal mais acometido pela enfermidade, porém os cães também podem sofrer infecção por esta micose. Objetivou-se relatar um caso de criptococose canina na cidade de Aracaju, Sergipe, devido aos poucos relatos de casos descritos na literatura envolvendo paciente canino com lesões de pele, por isso a importância do registro deste caso.

Palavras-chave: Cetoconazol, citologia, micose profunda, zoonose

\section{Cryptococcosis skin on a canine: Case Report}

\begin{abstract}
Cryptococcosis is a multisystem fungal disease opportunistic character, world-occurrence, affects the most diverse animals, including humans, and the cats is the species most affected by the disease, but dogs can also suffer infection this ringworm. This study aimed to report a case of canine cryptococcosis in the city of Aracaju, Sergipe, due to the few case reports in the literature involving canine patient with skin lesions, so the importance of the record of this case
\end{abstract}

Keywords: Ketoconazole, citology, deep mycosis, zoonosis

\section{Criptococosis cutánea en canino: Reporte de un caso}

RESUMEN. La criptococosis es una enfermedad fúngica multisistémica de carácter oportunista, de ocurrencia mundial, afecta a los más diversos animales, inclusive los seres humanos, siendo los felinos, la especie más afectada por la enfermedad, sin embargo los perros también pueden sufrir la infección por esta micosis. Este estudio tiene por objetivo relatar un caso de criptococosis canina en la ciudad de Aracaju, Brasil, debido a los pocos casos reportados en la literatura involucrando paciente canino con lesiones en la piel, por eso la importancia del registro de este caso.

Palabras clave: Ketoconazol, citología, micosis profunda, zoonosis

\section{Introdução}

As afecções de pele são comuns na rotina clínica veterinária, sendo que muitas delas apresentam potencial zoonótico e devem ser avaliadas criteriosamente, a fim de impedir a disseminação para os seres humanos. Os fungos são responsáveis por boa parte dessas infecções, estes disseminados nos mais diversos tipos de ambientes (Queiroz, 2008).

A criptococcose é uma micose sistêmica oportunista, com distribuição cosmopolita, pode 
acometer humanos, felinos, caprinos, equinos, bovinos e caninos, bem como os animais silvestres. $\mathrm{O}$ agente causador desta enfermidade possui boa resistência a fatores ambientes, o que garante sua permanência no meio ambiente por longos períodos de tempo (Silva et al., 2012). Os animais acometidos, geralmente apresentam quadro de imunossupressão, pois muitos destes, muito provavelmente já entraram em contato com $o$ agente em algum período de sua vida.

A estreita relação dos homens com os animais aumenta a cada dia, sendo assim a sanidade dos animais de estimação é de extrema importância, pois essa doença causa prejuízos econômicos aos tutores desses animais, como também instabilidade emocional a eles, quando, por exemplo, esses animais vêm a óbito, levando em consideração que esses animais são criados como membros da família (Oliveira, 2005). Em relação ao potencial zoonótico da criptococose é importante frisar que esta enfermidade pode causar serias lesões cutâneas, sistêmicas e principalmente ao sistema nervoso, podendo levar a pessoa acometida a óbito, com isso existe certa preocupação no âmbito de saúde pública (Castellá et al., 2008).

Objetivou-se relatar um caso de criptococose cutânea canina ocorrido no Hospital Veterinário Dr. Vicente Borelli em Aracaju-SE, bem como descrever os sinais clínicos, a forma que foi realizado o diagnóstico, tratamento e a resposta terapêutica instituída.

\section{Relato de caso}

Foi atendida no Hospital Veterinário Dr. Vicente Borelli, em Aracaju, Sergipe, uma cadela, sem raça definida, 2 anos, pesando $15 \mathrm{Kg}$, com a queixa principal de verrugas na região da face, com tempo aproximadamente de 15 dias de aparecimento destas lesões.

Em relação à imunização, o animal tinha recebido a vacina antirrábica, ela também havia sido vermifugada. Tomava banho com frequência de pelo menos uma vez por semana, e sua alimentação consistia em ração e alimentação humana. Quanto a sua habitação, ela vive em casa, está não possuindo pisos como revestimento e tem como contactante outro canino. A cadela não foi submetida a nenhum tratamento anterior. Durante o exame físico geral não foram observadas alterações no sistema urinário, respiratório, locomotor e nervoso, o sistema tegumentar apresentava lesões com aparência de verrugas nodulares (Figuras 1 e 2), de consistência dura, na cabeça as quais vinham apresentando prurido. No exame clínico sua temperatura estava dentro da normalidade, apresentando $37,7{ }^{\circ} \mathrm{C}$, linfonodos pré-escapulares, submandibulares e poplíteos aumentados, mucosas normocoradas, também apresentava hidratação adequada. A frequência cardíaca estava dentro dos padrões fisiológicos normais, $152 \mathrm{bpm}$ (batimentos por minuto), frequência respiratória apresentou-se dentro da normalidade, com $24 \mathrm{mpm}$ (movimentos/min).

Os exames complementares realizados para identificação do agente da lesão foram: Citologia e raspado cutâneo. Também foi feito teste rápido para leishimania, DPP ${ }^{\circledR}$ Leishmaniose Visceral Canina, o qual apresentou resultado negativo, assim como o raspado cutâneo.

No exame citológico, foi realizada a citologia aspirativa por agulha fina (CAAF). Com auxílio de uma agulha hipodérmica $25 \times 7$ acoplada a uma seringa de $5 \mathrm{ml}$ realizou-se várias punções da massa, obtendo-se material por capilaridade e em seguida, foram confeccionadas lâminas através de esfregaço desse material, sendo as mesmas coradas pela técnica de panótico rápido e encaminhadas para leitura, sendo evidenciado a presença de Cryptococcus sp apontadas pelas setas, demonstrado na (Figura 3). De acordo com a técnica descrita por Martins et al,. 2008. Diante do diagnóstico obtido, o animal foi submetido a uma conduta terapêutica fazendo uso do cetaconazol $(20 \mathrm{mg} / \mathrm{kg})$ a cada 24 horas durante 90 dias. O animal respondeu de forma satisfatória ao tratamento utilizado, com isso ocorreu o desaparecimento das lesões cutâneas da face do paciente, conforme a (Figura 4).

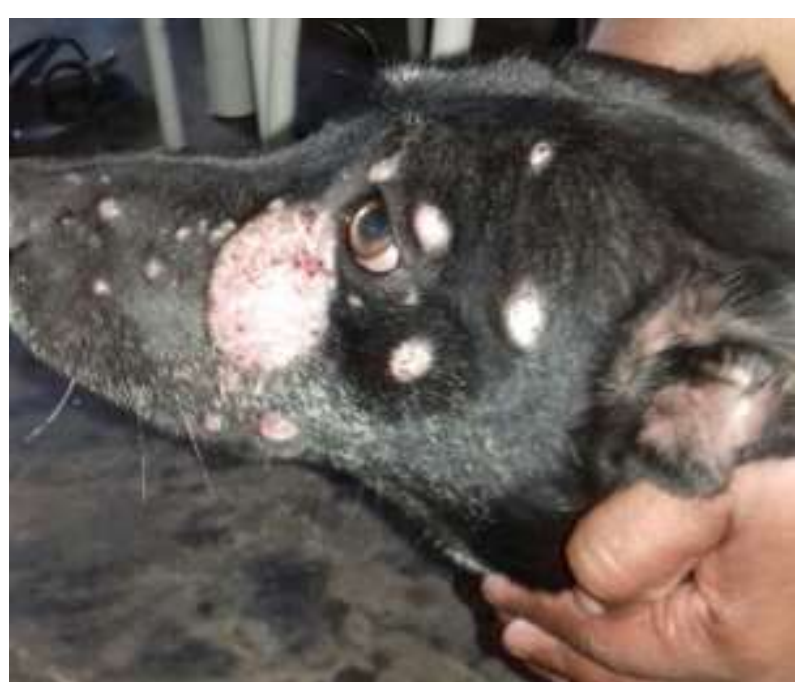

Figura 1. Lesões nodulares na face. Fonte: Arquivo pessoal. 


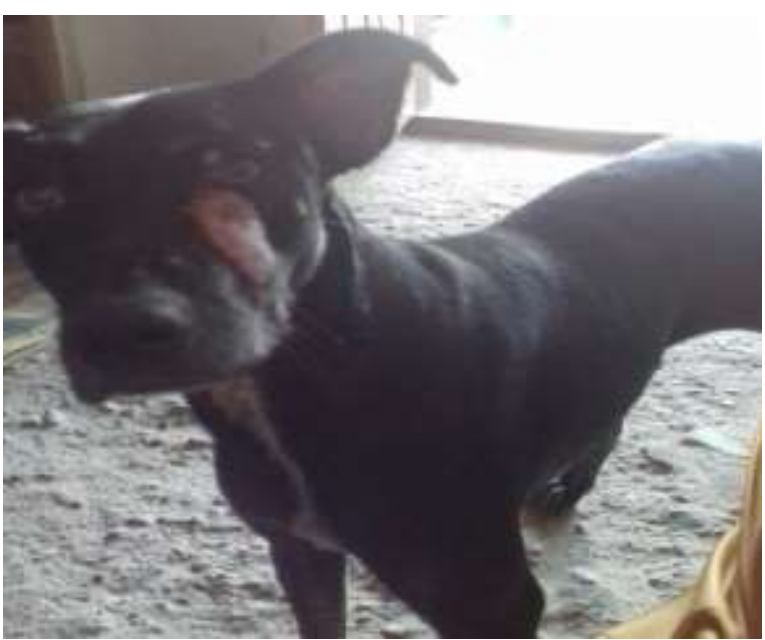

Figura 2. Lesões nodulares na face. Fonte: Arquivo pessoal.

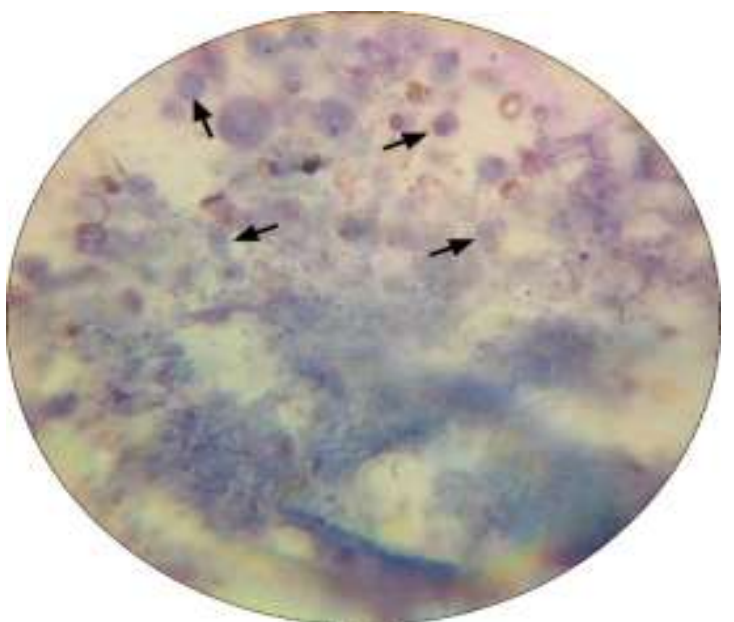

Figura 3. Exame citológico e detecção do Cryptococcus sp. Fonte: Arquivo pessoal.

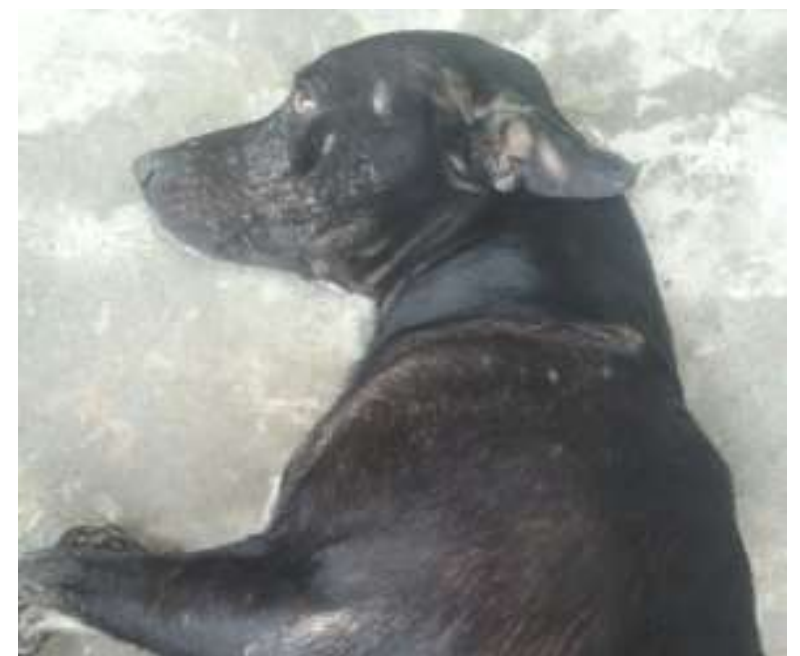

Figura 4. Cadela pós-tratamento e resolução das lesões de pele. Fonte: Arquivo pessoal.

\section{Resultados e Discussão}

A frequência da criptococose em cães é menor que os gatos, por possuírem características de caçadores e têm maior liberdade em seus deslocamentos, além de questões imunológicas, principalmente relacionadas a leucemia felina (FeLV) e pelo vírus da imunodeficiência felina (FIV), doenças essas que causam limitações quanto a resposta imunológica dos gatos (Castellá et al., 2008).

De acordo com Larsson et al. (2003), pacientes caninos com criptococose a manifestação clinica geralmente é com comprometimento neurológico e oftálmico, e, com menor frequência lesões de pele, como visto neste caso, isso leva a hipótese de que fato do animal ser mantido em local onde havia contato com terra, a manifestação da enfermidade foi no sistema tegumentar.

Segundo Conceição and Santos (2010) as lesões consistem em nódulos e massas tumorais, podendo estar ulcerada ou não, como também secreção purulenta, principalmente nas narinas, lábios, leito ungueal e região inguinal, no prepúcio e na região sacro lateral. Apesar do animal do presente relato não apresentar lesões no prepúcio, na região sacral e leito ungueal, o mesmo apresentava lesões na face, com aspecto semelhante ao descrito pelos autores supracitados, porém não apresentavam úlceras.

Guedes et al. (2000) afirmam que o diagnóstico utilizando a citologia aspirativa por agulha fina (CAAF) tem se demonstrado efetivo na resolução de casos como esse pois existem inúmeras dermatopatias com sinais clínicos semelhantes, sendo assim, permitindo a instituição de uma conduta terapêutica de acordo com o agente envolvido, com isso colaborando para eliminação do fungo causador desta infecção, assim como aconteceu neste relato.

O tratamento realizado para alcançar a cura das lesões cutâneas apresentadas neste caso lançou mão do uso de cetaconazol, com isso foi instituída a dose de $(20 \mathrm{mg} / \mathrm{kg})$ a cada 24 horas durante 90 dias, apresentando-se favorável na consolidação das lesões apresentadas no quadro clínico do paciente. De acordo com Nobre et al. (2002), o cetaconazol possui amplo potencial, podendo ser utilizado para tratamento de micoses sistêmicas, assim como as superficiais. Esses autores sugerem dosagens de 5-30mg de cetoconazol $/ \mathrm{kg} /$ dia para o tratamento de micoses caninas e felinas.

Em relação ao prognóstico do animal foi apontado como bom neste relato de caso, o qual apresentava a doenças por meio de lesões cutâneas, por ter havido diagnóstico prévio, como também o não comprometimento sistêmico pelo 
fungo, e nem infecção do sistema nervoso central, se mostrou favorável ao tratamento preconizado para resolução das lesões. De acordo com Birchard and Sherding (2008), os pacientes sem envolvimento com do sistema nervoso central o prognóstico considerado é bom, porém reservado para os que apresentam alterações neurológicas e sistêmicas da doença.

\section{Conclusão}

A criptococose canina é pouco comum na rotina clínica veterinária, com isso a divulgação de resultados como esses são importantes, pois aumentam o conhecimento acerca da manifestação clínica tegumentar desta doença.

O diagnóstico utilizando a citologia aspirativa por agulha fina foi fundamental para elucidação deste caso, contribuído para descartar outras enfermidades que possuem a mesma sintomatologia e sinais clínicos, assim como instituir uma conduta terapêutica adequada para tratamento do canino. O tratamento utilizando cetaconazol se mostrou eficaz na resolução das lesões cutâneas apresentadas na face do paciente.

\section{Referências bibliográficas}

Birchard, S. J. \& Sherding, R. G. 2008. Manual Saunders: clínica de pequenos animais, São Paulo.

Castellá, G., Abarca, M. L. \& Cabañes, F. J. 2008. Criptococosis y animales de compañía. Revista Iberoamericana de Micología, 25, S19-S24.

Conceição, L. G. \& Santos, L. S. 2010. Sistema tegumentar. In: Conceição, L. G. (ed.) Patologia veterinária. Roca, São Paulo.

Guedes, R. M. C., Zica, K. G. B., Coelho-Guedes, M. I. M. \& Oliveira, S. R. 2000. Acurácia do exame citológico no diagnóstico de processos inflamatórios e proliferativos dos animais domésticos. Arquivo Brasileiro de Medicina Veterinária e Zootecnia, 52, 437-439.
Larsson, C. E., Otsuka, M., Michalany, N. S., Barros, P. S. M., Gambale, W. \& Safatle, A. M. V. 2003. Criptococose canina: relato de caso. Arquivo Brasileiro de Medicina Veterinária e Zootecnia, 55, 533-538.

MartinsI, D. B., Barbosa, A. L. T., Cavalheiro, A., Lopes, S. T. A, Santurio, J. M., Schossler, J. E. \& Mazzanti, A. 2008. Diagnóstico de criptococose canina pela citologia aspirativa por agulha fina. Ciência Rural, 38, 826-829.

Nobre, M. O., Silva, P. N., Meireles, M. C. \& Ferreiro, L. 2002. Drogas antifúngicas para pequenos e grandes animais. Ciência Rural, $32,175-184$.

Oliveira, I. A. 2005. Pesquisa de criptococose em cães atendidos no Hospital de clínicas veterinarias da UFRGS, Porto Alegre, Brasil. Departamento de Vetrinária. Universidade Federal do Rio Grande do Sul, Porto Alegre.

Queiroz, J. P. A. F. 2008. Criptococose-Uma revisão bibliográfica. Acta Veterinaria Brasilica, 2, 32-38.

Silva, B. K., Freire, A. K., Bentes, A. D. S., Sampaio, I. D. L., Santos, L. O., Santos, M. S. \& Souza, J. V. 2012. Characterization of clinical isolates of the Cryptococcus neoformans-Cryptococcus gattii species complex from the Amazonas State in Brazil. Revista Iberoamericana de Micologia, 29, 4043.

\section{Article History:}

Received 27 October 2016

Accepted 8 December 2016

Available on line 2 February 2017

License information: This is an open-access article distributed under the terms of the Creative Commons Attribution License 4.0, which permits unrestricted use, distribution, and reproduction in any medium, provided the original work is properly cited. 